\title{
Aa. Vv., Translatio: traduire et adapter les Anciens, études réunies par Corinne Bonnet et Florence Bouchet
}

\section{Maurizio Busca}

\section{(2) OpenEdition}

Journals

\section{Edizione digitale}

URL: http://journals.openedition.org/studifrancesi/1107

DOI: 10.4000/studifrancesi. 1107

ISSN: 2421-5856

\section{Editore}

Rosenberg \& Sellier

\section{Edizione cartacea}

Data di pubblicazione: 1 novembre 2014

Paginazione: 578

ISSN: 0039-2944

\section{Notizia bibliografica digitale}

Maurizio Busca, « Aa. VV., Translatio: traduire et adapter les Anciens, études réunies par Corinne Bonnet et Florence Bouchet », Studi Francesi [Online], 174 (LVIII | III) | 2014, online dal 01 novembre 2014, consultato il 18 septembre 2020. URL : http://journals.openedition.org/studifrancesi/1107 ; DOI : https://doi.org/10.4000/studifrancesi. 1107

\section{Questo documento è stato generato automaticamente il 18 settembre 2020.}

\section{cc) (†) $\odot$}

Studi Francesi è distribuita con Licenza Creative Commons Attribuzione - Non commerciale - Non opere derivate 4.0 Internazionale. 


\title{
Aa. Vv., Translatio: traduire et adapter les Anciens, études réunies par Corinne Bonnet et Florence Bouchet
}

\author{
Maurizio Busca
}

\section{NOTIZIA}

AA. VV., Translatio: traduire et adapter les Anciens, études réunies par Corinne BONNET et Florence BOUCHET, Paris, Classiques Garnier, 2013 («Rencontres», 52), pp. 331.

1 Il volume riunisce i contributi del seminario Patrimoine, littérature, société (Université Toulouse II-Le Mirail, 2008-2010), avente per oggetto d'indagine la traduzione e strutturantesi secondo una prospettiva diacronica e pluridisciplinare. Benché il campo di ricerca sia estremamente esteso (sono prese in esame traduzioni elaborate dall'antichità classica a oggi, dalla Grecia alla Scandinavia) e gli approcci metodologici siano diversi, i contributi si organizzano secondo sezioni tematiche ben definite, nelle quali il volume trova una sua coesione. La prima parte si articola intorno alle domande fondamentali che si pone il traduttore: perché e come? Come preservare la sacralità di un testo religioso in traduzione? Come rendere giustizia al "genio" del poeta? Nella seconda parte viene invece studiata la traduzione come dispositivo creatore di tradizione e di identità culturale. La terza parte, infine, esamina alcune operazioni di modernizzazione di testi antichi, operazioni che si rivelano avere per lo più un fondo ideologico.

2 I contributi raccolti sono i seguenti: Corinne BONNET, Florence BOUCHET, Introduction, pp. 9-17. Prima parte («Penser la traduction»): Bruno ROCHETTE, «Traduire ou ne pas traduire». Un dilemme bien connu des auteurs grecs et latins, pp. 21-38; Pierre-Emmanuel DAUZAT, L'ombre portée de la traduction. Des erreurs initiales, de la Genèse à Goethe, pp. 39-57; Olivier GUERRIER, Auteur-Traducteur-Public aux XVI et XVII siècles. Enjeux et mutations d'une relation triangulaire, pp. 59-70; Marine MOLINS, L'Antiquité comme source d'inspiration et matière à 
réflexion chez les traducteurs de la Renaissance. Les choix de Charles Fontaine, pp. 71-92; JeanNoël PASCAL, Naturaliser Virgile en vers français. Le cas des Bucoliques et des Géorgiques (1770-1820), pp. 93-106. Seconda parte («L'Antique comme enjeu de transferts culturels»): Alexandra DARDENAY, Rome, les Romains et l'art grec. Translatio, interpretatio, imitatio, æmulatio, pp. 109-137; Daniel W. LACROIX, La traduction des textes latins en prose norroise au Moyen Âge, pp. 139-155; Francine MORA, Des translations différentes: les versions manuscrites du "Roman d'Eneas", du XII au XIV siècle, pp. 157-174; Anne-Hélène KLINGERDoLlé, Platon latin, Platon françoys: quelques traductions de la Renaissance. Philosophie de l'amour et "fictions poétiques», pp. 175-194; Luigi-Alberto SANCHI, Guillaume Budé, de la translatio studiorum au "De Transitu", pp. 195-209. Terza parte (Moderniser l'Antique: innover dans la tradition): Violaine GIACOMOTTO-CHARRA, La clémence de la terre. Histoire d'un topos plinien à la Renaissance, pp. 213-238; Laure LÉVÊQUE, L'Antiquité au présent. Lire et relire le politique, 1780-1850, pp. 239-257; Cédric CHAUVIN, Traduire Homère aujourd'hui. L'“Odyssée" de Philippe Jaccottet, pp. 259-284; Jean-Yves LAURICHESSE, La guerre en latin. Claude Simon et la bataille de Pharsale, pp. 285-303.

Diversi sono gli articoli sul XVI secolo. Il contributo di GUERRIER è dedicato ai rapporti fra traduttore, opere tradotte e pubblico: l'A. segue l'evolversi dello statuto di traduttore, concentrandosi sulla figura di Amyot e sulla ricezione delle sue traduzioni tra Cinque e Seicento. MOLINS affronta la tematica della traduzione come occasione di riflessione sulla lingua vernacolare e sul suo rapporto con le lingue classiche, studiando in particolare il caso di Charles Fontaine traduttore e commentatore di Ovidio e Publilio Siro. L'articolo di KLINGER-DOLLÉ analizza un corpus di tre testi incentrati sulla questione filosofica dell'amore secondo Platone (la traduzione integrale del Lysis di Bonaventure Des Périers, l'adattamento poetico del mito di Androgino di Antoine Héroët e la traduzione commentata del Simposio di Louis Le Roy), testi che illustrano diverse forme di reazione alle traduzioni di Marsilio Ficino. Seguendo il percorso biografico di Budé, SANCHI rileva l'importanza capitale di alcuni suoi testi programmatici (in particolare la prefazione del De Asse e il De Transitu) per lo sviluppo degli studi umanistici - non solo in Francia - e per la difesa dello studio dei testi greci. Infine, attraverso l'esame di diverse riscritture rinascimentali di un locus pliniano (l'elogio della clemenza della terra, Hist. Nat. II, 63, rielaborato da Pontus de Tyard, Pierre Boaistuau, Antoine du Pinet e Guillaume du Bartas), GIACOMOTTO-CHARRA mostra come nel Rinascimento la translatio sia un processo rivolto anche all'appropriazione e all'attualizzazione dei testi, un processo avente talvolta l'esito di assicurare ad un frammento isolato una circolazione autonoma nella cultura d'arrivo. Una bibliografia generale (pp. 305-517), ripartita fra studi diacronici e storici, completa il volume. 